\title{
Pathology review impacts clinical management of patients with Tl-T2 bladder cancer
}

\author{
Samer L. Traboulsi, MD'; Fadi Brimo, MD, FRCP(C)'; Yutong Yang, MD²; Chelsea Maedler, $M D^{2}$; \\ Noémie Prévost, MSC'; Simon Tanguay, MD, FRCS(C)'; Armen G. Aprikian, MD, FRCS(C)'; \\ Wassim Kassouf, MD, CM, FRCS(C)
}

'Division of Urology; 2Department of Pathology; McGill University Health Centre, Montreal, QC, Canada

Cite as: Can Urol Assoc J 2017;11 (6):188-93 http://dx.doi.org/10.5489/cuai.4126

\section{Abstract}

Introduction: We sought to evaluate the contemporary role of a pathology review on management implications of patients with bladder cancer.

Methods: A total of 98 consecutive specimens from transurethral resections in patients with suspected bladder tumours were reviewed at our institution by genitourinary pathologist. Patients were classified into risk groups according to pathology reports obtained before and after review. A management course was proposed according to local institutional practice patterns and main urological guidelines.

Results: Overall, $34.7 \%$ of pathological reviews had significant changes associated with management implications, the majority of which were due to changes in risk category (and/or stage). On review pathology, 12 patients were recommended radical cystectomy instead of conservative management and two patients avoided radical cystectomy. Six patients initially staged as T1 and whose staging did not change after review had a proposed change in management in the form of early cystectomy as a treatment option, as they were deemed very high-risk secondary to high-risk features (such as carcinoma in situ or lymphovascular invasion found on review). Ten patients initially staged as T2 demonstrated high-risk features on review.

Conclusions: Review by genitourinary pathologist remains important, as it defines more clearly the tumour risk category and influences the management of T1-T2 bladder cancer patients. A complete initial pathological report has the potential to further decrease the discrepancy between initial and review reports.

\section{Introduction}

Despite the implementation of the TNM and World Health Organization (WHO) classifications for pathological reporting, interpretation of bladder lesions still pose a challenge for pathologists. This is manifested by a large degree of interobserver variability in reporting between the initial pathologist and the reviewer.

As treatment in bladder cancer depends heavily on pathology reports, any change in pathological interpretation can bring about significant changes in patient management. It has been reported that among all genitourinary cancers, a multidisciplinary review of bladder cancer cases (including pathological review) may result in the highest percentage of change in diagnosis and treatment. ${ }^{1}$ No significant change in management was brought about by different pathological interpretation for low- and intermediate-risk non-muscleinvasive bladder cancer (NMIBC)., ${ }^{2,3}$ In high-risk tumours, however, variation in pathological reading significantly affects prognosis. ${ }^{2,4}$ For this reason, a number of institutions require a review of pathological specimens in the setting of surgical consultation in order to improve pathologic accuracy and patient care.

We evaluated the implications of stage and grade discrepancy, in addition to other prognostic factors, such as carcinoma in situ (CIS), lymphovascular invasion (LVI), and variant histology $(\mathrm{VH})$, on the risk category in review pathology of patients with bladder cancer and its subsequent influence on treatment strategy.

\section{Methods}

After obtaining the approval of our institutional review board, we collected data on all consecutive transurethral biopsies received between 2011 and 2014 from outside hospitals, which were reviewed prospectively. Our institution's genitourinary pathologist, blinded to the initial report, reviewed a total of 98 pathology consultations.

Pathological staging and grading were assigned according to the 7th American Joint Committee on Cancer (AJCC)/ TNM staging system ${ }^{5}$ and the latest $\mathrm{WHO}^{6,7}$ respectively. The review pathology report was consistent with the international recommendations for transurethral resection of 
bladder tumour (TURBT) pathology reporting ${ }^{8,9}$ and included the revised histological diagnosis, $T$ stage, grade, presence of muscularis propria in the specimen, LVI, and CIS. Involvement of prostatic tissue and presence of variant histology $(\mathrm{VH})$ were commented on if found. Using the American/ Society of Urologic Oncology (SUO) and Canadian bladder cancer guidelines, ${ }^{10,11}$ as well as our institutional guidelines of care, each case was assigned a tumour risk category with the initial pathological report and another one according to the review pathology report. Preferred management was matched to the proposed risk category.

NMIBC (Ta and T1) was divided into low- and intermediate-risk (NMIBC-LR), high-risk (NMIBC-HR), or very highrisk (NMIBC-VHR) tumours. Tumours invading the muscularis propria were divided into muscle-invasive (MIBC), and high-risk muscle invasive tumours (MIBC-HR), consistent with previous reports ${ }^{12,13}$ (Table 1).

NMIBC-LR included cases of Ta low-grade (TaLG). Consistent with current guidelines, NMIBC-HR included all high-grade disease, T1, or CIS. NMIBC-VHR included all T1HG tumours with adverse features, such as concomitant CIS, LVI, or VH (micropapillary, nested, plasmacytoid, or sarcomatoid features). Microcystic, glandular, and squamous variants were not considered worse prognostic indicators due to lack of convincing results in the literature concerning significance. ${ }^{14}$ We did not include variables such as multifocality, tumour size, and recurrence in our risk stratification.

Muscle-invasive tumours were divided into MIBC, which included all muscle-invasive (T2) tumours with or without concomitant CIS or squamous/glandular/microcystic variants. MIBC, in the presence of LVI, or micropapillary/ plasmacytoid/sarcomatoid variants, or in the presence of prostatic stromal invasion (T4a) was considered high-risk (MIBC-HR). ${ }^{12,15}$

Changes in management matched to the risk category were divided into major significant changes and significant changes. Kappa statistics were used to assess the level of agreement between the initial pathologist and the reviewing pathologist vis-à-vis risk category distribution and presence

\begin{tabular}{lccc}
\hline \multicolumn{4}{l}{ Table 1. Tumour distribution by stage and histology in } \\
original pathology & Histology & $\mathbf{n}(\%)$ \\
\hline Stage & $\mathbf{n}(\%)$ & Benign & $5(5.1 \%)$ \\
\hline Benign & $5(5.1 \%)$ & Urothelial & $86(87.8 \%)$ \\
CIS & $3(3.1 \%)$ & Small-cell & $2(2.0 \%)$ \\
TaLG & $2(2.0 \%)$ & Poorly differentiated & $2(2.0 \%)$ \\
TaHG & $3(3.1 \%)$ & Squamous-cell & $1(1.0 \%)$ \\
T1 & $28(28.6)$ & Sarcoma & $1(1.0 \%)$ \\
T2 & $55(56.1 \%)$ & Primary enteric-type & $1(1.0 \%)$ \\
T4a & $2(2.0 \%)$ & adenocarcinoma \\
Total & $98(100 \%)$ & & $98(100 \%)$ \\
\hline \multicolumn{4}{l}{ CIS: carcinoma in situ; TaHG: Ta high-grade; TaLG: Ta low-grade. } \\
\hline
\end{tabular}

or absence of CIS and LVI in the reports. Kappa statistics were performed using the Statistical Analysis System Software (version 9; SAS Institute, Cary, NC, U.S.)

\section{Results}

\section{Original and review pathology}

The stage and histology distribution of tumours in the original reports are shown in Table 1. Among 78 patients with urothelial carcinoma $(U C)$ who presented with either stage $\mathrm{T} 1$, $\mathrm{T} 2$, or $\mathrm{T} 4 \mathrm{a}$, the presence or absence of $\mathrm{LVI}$, concomitant $\mathrm{CIS}$, and VH was reported only in 27 (34.6\%), 20 (25.6\%), and $16(20.5 \%)$ cases, respectively. Review pathology commented on LVI and CIS in $90 \%$ and $93 \%$ of invasive cases, respectively. When reported in the initial pathology, there was agreement between presence or absence of LVI and CIS in $83.3 \%$ (Kappa coefficient $=0.56 ; 95 \%$ confidence interval [CI] $0.21-0.90$ ) and $100 \%$, respectively between the original and review pathology. Regarding $\mathrm{VH}$, our review detected 16 $\mathrm{VH}$ types that weren't present in outside pathology reports. Importantly, six of the missed variants are well-known to be associated with a more aggressive clinical outcome (micropapillary, nested, and sarcomatoid). Furthermore, significant T-stage changes were noted on review and associated with subsequent management implications (Table 2).

\section{Risk category reclassification}

When divided into risk categories, there were two NMIBCLR cases in the initial reports. After review, one remained NMIBC-LR, whereas one was reclassified as MIBC. Among 29 cases initially classified as NMIBC-HR, 14 (48.3\%) remained NMIBC-HR, whereas seven $(24.1 \%)$ were reclassified as NMIBC-VHR, five $(17.2 \%)$ as MIBC, and three $(10.3 \%)$ as MIBC-HR. There were five NMIBC-VHR cases initially; four remained in the same category after review $(80.0 \%)$, whereas one $(20.0 \%)$ was reclassified as MIBC. There were 44 MIBC tumours in the original reports; $28(63.6 \%)$ remained in the same risk category after review, whereas 15 (34.1\%) demonstrated high-risk features and were reclassified as MIBC-HR, and one (2.3\%) was downstaged to NMIBC-HR. All 13 cases of MIBC-HR in the original report remained as such after review (Table 3 ).

\section{Impact with changes in clinical management}

Discrepancies found between the original and review pathologies would have brought about a change in treatment plans in 34 cases overall (Table 4); 29 patients due to a change in risk category (and/or T stage), three patients due to new information on the presence/invasion of muscularis 
Traboulsi et al.

\begin{tabular}{|c|c|c|c|c|}
\hline \multirow{2}{*}{$\begin{array}{l}\text { Initial stage } \\
\text { (n) } \\
\mathrm{CIS}=3\end{array}$} & \multicolumn{2}{|c|}{ Review stage n (\%) } & \multirow{2}{*}{$\begin{array}{c}\text { Change in management after } \\
\text { review, } \mathbf{n}(\%)\end{array}$} & \multirow[t]{2}{*}{ Causes of change in management } \\
\hline & Remained CIS & $2(66.7 \%)$ & & \\
\hline & Upstaged to T1 & 0 & & \\
\hline & Upstaged to T2 & $1(33.3 \%)$ & $1(100 \%)$ & Review showed MIBC + LVI \\
\hline \multirow[t]{3}{*}{$\mathrm{Ta}=5$} & Remained Ta & $3(60.0 \%)$ & 0 & \\
\hline & Upstaged to $\mathrm{T} 1$ & $1(20.0 \%)$ & $1(100 \%)$ & Change in T category + CIS $1(100 \%)$ \\
\hline & Upstaged to T2 & $1(20.0 \%)$ & $1(100 \%)$ & Change in T category $1(100 \%)$ \\
\hline \multirow[t]{4}{*}{$\mathrm{T} 1=28$} & Remained T1 & $19(67.9 \%)$ & $6(31.6 \%)$ & CIS found on review 5 (83.3\%) \\
\hline & & & & LVI found on review $1(16.7 \%)$ \\
\hline & Upstaged to $\mathrm{T} 2$ & $8(28.6 \%)$ & $8(100 \%)$ & Change in T category $8(100 \%)$ \\
\hline & Downstaged to Ta & $1(3.6 \%)$ & 0 & \\
\hline \multirow[t]{6}{*}{$\mathrm{T} 2=55$} & Remained T2 & $54(98.2 \%)$ & $16(29.6 \%)$ & LVI found on review $6(37.5 \%)$ \\
\hline & & & & Variant histology on review 2 (12.5\%) \\
\hline & & & & $\mathrm{LVI}+$ variant on review $3(18.8 \%)$ \\
\hline & & & & Change in histologic diagnosis $2(12.5 \%)$ \\
\hline & & & & Unsure if MP present/invaded $3(18.8 \%)$ \\
\hline & Downstaged to $\mathrm{T} 1$ & 1 (1.8\%) & $1(100 \%)$ & No MP invasion on review \\
\hline
\end{tabular}

propria, and two patients due a change in histological diagnosis after review.

\section{Major significant treatment changes based on guidelines}

Out of those 34 proposed management changes, 14 were considered major significant changes mainly due to change in stage. In fact, 12 patients were recommended radical cystectomy because of muscularis propria invasion (Table 4). A radical cystectomy was avoided in a patient who was downstaged from T2 to T1 HG after review. Another radical cystectomy was avoided because the review showed a T2 tumour with a possible risk of misinterpretation of muscularis mucosa for muscularis propria. In patients who were upstaged to $\mathrm{T} 2$ on review and underwent cystectomy, pathology on cystectomy specimen confirmed $\geq \mathrm{pT} 2$ in $75 \%$ of cases.

\section{Other significant treatment changes based on institutional practices}

An additional 20 cases were considered significant changes primarily based on the institutional practices. Eleven patients with T2 disease were strongly advised neoadjuvant chemotherapy (NAC) before cystectomy because high-risk features were found on review (risk category change from MIBC to MIBC-HR). Two patients initially diagnosed with poorly differentiated carcinoma had their histological diagnosis changed into $U C$ after review. In those two cases, a radical cystectomy was proposed. Six T1 patients (whose staging didn't change after review) were proposed early cystectomy as an option since they were reclassified from NMIBC-HR to NMIBC-VHR secondary to high-risk features (CIS and LVI) recognized on review.

\begin{tabular}{lcccc}
\hline \multicolumn{6}{l}{ Table 3. Conformity between original and review pathology by risk stratification } \\
\hline Risk category & Original $(\mathbf{n})$ & Review $(\mathbf{n})$ & Interpathologist agreement (\%) & Interpathologist agreement (Kappa coefficient) \\
\hline Benign & 5 & 5 & $100 \%$ & - \\
NMIBC-LR & 2 & 14 & $50.0 \%$ & - \\
NMIBC-HR & 29 & 4 & $48.3 \%$ & $0.55(95 \%$ Cl $0.36-0.73)$ \\
NMIBC-VHR & 5 & 28 & $80.0 \%$ & - \\
MIBC & 44 & 13 & $63.6 \%$ & 0.52 (95\% Cl 0.35-0.69) \\
MIBC-HR & 13 & $100 \%$ & - \\
Interpathologist agreement for all risk categories (Kappa coefficient): & 0.55 (95\% Cl 0.43-0.67) \\
\hline Cl: confidence interval; MIBC: muscle-invasive bladder cancer; MIBC-HR: high-risk muscle-invasive bladder cancer; NMIBC: non-muscle-invasive bladder cancer; NMIBC-HR: high-risk non- \\
muscle-invasive bladder cancer; NMIBC-LR: low-risk non-muscle-invasive bladder cancer; NMIBC-VHR: very-high-risk non-muscle-invasive bladder cancer.
\end{tabular}




\begin{tabular}{|c|c|c|c|c|c|}
\hline \multicolumn{6}{|c|}{ Major significant treatment changes } \\
\hline $\begin{array}{l}\text { Case } \\
\text { no. }\end{array}$ & $\begin{array}{c}\text { Original } \\
\text { diagnosis }\end{array}$ & Review diagnosis & $\begin{array}{l}\text { Risk group } \\
\text { stratification }\end{array}$ & $\begin{array}{c}\text { Change in } \\
\text { management }\end{array}$ & Remarks \\
\hline 1 & TaLG & $\mathrm{T} 2$ & NMIBC-LR $\rightarrow$ MIBC & $\begin{array}{c}\text { Conservative } \\
\text { surveillance } \rightarrow \mathrm{RC}\end{array}$ & \\
\hline 2 & $\mathrm{CIS}$ & $\mathrm{T} 2+\mathrm{LVI}+\mathrm{CIS}$ & $\mathrm{NMIBC}-\mathrm{HR} \rightarrow \mathrm{MIBC}-\mathrm{HR}$ & $\mathrm{BCG} \rightarrow \mathrm{NAC}+\mathrm{RC}$ & \\
\hline 3 & T1HG & $\mathrm{T} 2$ & $\mathrm{NMIBC}-\mathrm{HR} \rightarrow \mathrm{MIBC}$ & reTURBT + BCG $\rightarrow R C$ & \\
\hline 4 & T1HG & $\mathrm{T} 2$ & $\mathrm{NMIBC}-\mathrm{HR} \rightarrow \mathrm{MIBC}$ & reTURBT + BCG $\rightarrow$ RC & \\
\hline 5 & T1HG & $\mathrm{T} 2$ & $\mathrm{NMIBC}-\mathrm{HR} \rightarrow \mathrm{MIBC}$ & reTURBT + BCG $\rightarrow \mathrm{RC}$ & \\
\hline 6 & T1HG & $\mathrm{T} 2$ & $\mathrm{NMIBC}-\mathrm{HR} \rightarrow \mathrm{MIBC}$ & reTURBT + BCG $\rightarrow$ RC & \\
\hline 7 & T1HG & $\mathrm{T} 2+\mathrm{CIS}$ & $\mathrm{NMIBC}-\mathrm{HR} \rightarrow \mathrm{MIBC}$ & reTURBT + BCG $\rightarrow$ RC & \\
\hline 8 & T1HG & T2+ LVI & $\mathrm{NMIBC}-\mathrm{HR} \rightarrow \mathrm{MIBC}-\mathrm{HR}$ & $\begin{array}{c}\text { reTURBT + BCG } \rightarrow \\
\quad N A C+R C\end{array}$ & \\
\hline 9 & T1HG & $\begin{array}{l}\mathrm{T} 2+\mathrm{LVI}+\mathrm{CIS}+ \\
\text { sarcomatoid }\end{array}$ & $\mathrm{NMIBC}-\mathrm{HR} \rightarrow \mathrm{MIBC}-\mathrm{HR}$ & $\begin{aligned} \text { reTURBT } & +B C G \rightarrow N A C \\
& +\mathrm{RC}\end{aligned}$ & \\
\hline 10 & T1HG+ LVI & $\mathrm{T} 2$ & NMIBC-VHR $\rightarrow$ MIBC & $\begin{array}{c}\text { Consider early } \mathrm{RC} \rightarrow \\
\text { definite } \mathrm{RC}\end{array}$ & \\
\hline 11 & $\mathrm{~T} 2$ & $\mathrm{~T} 2$ & $\mathrm{MIBC} \rightarrow \mathrm{MIBC}$ & $\mathrm{RC} \rightarrow \mathrm{reTURBT}$ & Unsure if MP is invaded in review pathology \\
\hline 12 & $\mathrm{~T} 2$ & T1HG & $\mathrm{MIBC} \rightarrow \mathrm{NMIBC}-\mathrm{HR}$ & $\mathrm{RC} \rightarrow \mathrm{reTURBT}+\mathrm{BCG}$ & \\
\hline 13 & $\mathrm{~T} 2$ & $\mathrm{~T} 2+\mathrm{CIS}$ & $\mathrm{MIBC} \rightarrow \mathrm{MIBC}$ & reTURBT $\rightarrow$ RC & Unsure if MP is invaded in original pathology \\
\hline 14 & T2 & $\mathrm{T} 2+\mathrm{LVI}+\mathrm{CIS}$ & $\mathrm{MIBC} \rightarrow \mathrm{MIBC}-\mathrm{HR}$ & reTURBT $\rightarrow \mathrm{NAC}+\mathrm{RC}$ & Unsure if MP is invaded in original pathology \\
\hline \multicolumn{6}{|c|}{ Significant treatment changes based on institutional practice } \\
\hline $\begin{array}{l}\text { Case } \\
\text { no. }\end{array}$ & $\begin{array}{c}\text { Original } \\
\text { diagnosis }\end{array}$ & Review diagnosis & $\begin{array}{l}\text { Risk group } \\
\text { stratification }\end{array}$ & $\begin{array}{c}\text { Change in } \\
\text { management }\end{array}$ & Remarks \\
\hline 15 & $\begin{array}{c}\mathrm{TaHG}+(\mathrm{CIS} \\
\text { prostatic ducts) }\end{array}$ & $\begin{array}{l}\mathrm{T} 1 \mathrm{HG}+\mathrm{CIS}+(\mathrm{CIS} \\
\text { prostatic ducts })\end{array}$ & $\begin{array}{c}\text { NMIBC-HR } \rightarrow \text { NMIBC- } \\
\text { VHR }\end{array}$ & $\begin{array}{l}\text { TURP + BCG } \rightarrow \\
\text { consider early RC }\end{array}$ & \\
\hline 16 & T1HG & $\mathrm{T} 1 \mathrm{HG}+\mathrm{CIS}$ & $\begin{array}{c}\text { NMIBC-HR } \rightarrow \text { NMIBC- } \\
\text { VHR }\end{array}$ & $\begin{array}{l}\text { reTURBT + BCG } \rightarrow \\
\text { consider early } R C\end{array}$ & \\
\hline 17 & T1HG & $\mathrm{T} 1 \mathrm{HG}+\mathrm{CIS}$ & $\begin{array}{c}\text { NMIBC-HR } \rightarrow \text { NMIBC- } \\
\text { VHR }\end{array}$ & $\begin{array}{l}\text { reTURBT + BCG } \rightarrow \\
\text { consider early RC }\end{array}$ & \\
\hline 18 & T1HG & $\mathrm{T} 1 \mathrm{HG}+\mathrm{CIS}$ & $\begin{array}{c}\text { NMIBC-HR } \rightarrow \text { NMIBC- } \\
\text { VHR }\end{array}$ & $\begin{array}{l}\text { reTURBT + BCG } \rightarrow \\
\text { consider early RC }\end{array}$ & \\
\hline 19 & T1HG & $\mathrm{T} 1 \mathrm{HG}+\mathrm{CIS}$ & $\begin{array}{c}\text { NMIBC-HR } \rightarrow \text { NMIBC- } \\
\text { VHR }\end{array}$ & $\begin{array}{l}\text { reTURBT + BCG } \rightarrow \\
\text { consider early } \mathrm{RC}\end{array}$ & \\
\hline 20 & T1HG & $\mathrm{T} 1 \mathrm{HG}+\mathrm{CIS}$ & $\begin{array}{c}\text { NMIBC-HR } \\
\text { VHR NMIBC- }\end{array}$ & $\begin{array}{l}\text { reTURBT + BCG } \rightarrow \\
\text { consider early } R C\end{array}$ & \\
\hline 21 & T1HG & T1HG + LVI & $\begin{array}{c}\text { NMIBC-HR } \rightarrow \text { NMIBC- } \\
\text { VHR }\end{array}$ & $\begin{array}{l}\text { reTURBT + BCG } \rightarrow \\
\text { consider early RC }\end{array}$ & \\
\hline 22 & $\mathrm{~T} 2$ & $\mathrm{~T} 2+\mathrm{LVI}$ & $\mathrm{MIBC} \rightarrow \mathrm{MIBC}-\mathrm{HR}$ & $\begin{array}{l}\text { Unclear management } \\
\qquad \rightarrow \mathrm{NAC}+\mathrm{RC}\end{array}$ & $\begin{array}{l}\text { Change in histological diagnosis from poorly } \\
\text { differentiated } C A \rightarrow \text { urothelial carcinoma }\end{array}$ \\
\hline 23 & $\mathrm{~T} 2$ & T2 & $\mathrm{MIBC} \rightarrow \mathrm{MIBC}$ & $\begin{array}{l}\text { Unclear management } \\
\qquad \rightarrow \mathrm{RC}\end{array}$ & $\begin{array}{l}\text { Change in histological diagnosis from poorly } \\
\text { differentiated CA } \rightarrow \text { urothelial carcinoma }\end{array}$ \\
\hline 24 & T2 & $\mathrm{T} 2+\mathrm{LVI}$ & $\mathrm{MIBC} \rightarrow \mathrm{MIBC}-\mathrm{HR}$ & NAC before RC & \\
\hline 25 & $\mathrm{~T} 2$ & $\mathrm{~T} 2+\mathrm{LVI}$ & $\mathrm{MIBC} \rightarrow \mathrm{MIBC}-\mathrm{HR}$ & NAC before RC & \\
\hline 26 & $\mathrm{~T} 2$ & $\mathrm{~T} 2+\mathrm{LVI}$ & $\mathrm{MIBC} \rightarrow \mathrm{MIBC}-\mathrm{HR}$ & NAC before RC & \\
\hline 29 & $\mathrm{~T} 2$ & $\mathrm{~T} 2+\mathrm{LVI}$ & $\mathrm{MIBC} \rightarrow \mathrm{MIBC}-\mathrm{HR}$ & NAC before RC & \\
\hline 30 & $\mathrm{~T} 2$ & $\mathrm{~T} 2+\mathrm{LVI}$ & $\mathrm{MIBC} \rightarrow \mathrm{MIBC}-\mathrm{HR}$ & NAC before RC & \\
\hline 31 & $\mathrm{~T} 2$ & $\mathrm{~T} 2+$ nested & $\mathrm{MIBC} \rightarrow \mathrm{MIBC}-\mathrm{HR}$ & NAC before RC & \\
\hline 32 & $\mathrm{~T} 2$ & $\begin{array}{c}\mathrm{T} 2+\mathrm{LVI}+ \\
\text { micropapillary }\end{array}$ & $\mathrm{MIBC} \rightarrow \mathrm{MIBC}-\mathrm{HR}$ & NAC before RC & \\
\hline 33 & $\mathrm{~T} 2$ & $\begin{array}{c}\mathrm{T} 2+\mathrm{LVI}+ \\
\text { sarcomatoid }\end{array}$ & $\mathrm{MIBC} \rightarrow \mathrm{MIBC}-\mathrm{HR}$ & NAC before RC & \\
\hline 34 & $\mathrm{~T} 2$ & $\mathrm{~T} 2$ + LVI & $\mathrm{MIBC} \rightarrow \mathrm{MIBC}-\mathrm{HR}$ & NAC before RC & \\
\hline
\end{tabular}

BCG: bacillus Calmette-Guerin; CIS: carcinoma in situ; LVI: Iymphovascular invasion; MIBC: muscle-invasive bladder tumour; MIBC-HR: high-risk muscle-invasive bladder tumour; MP:

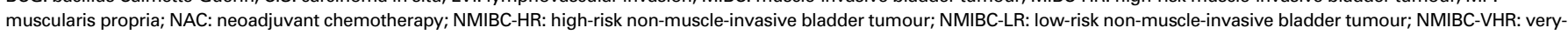

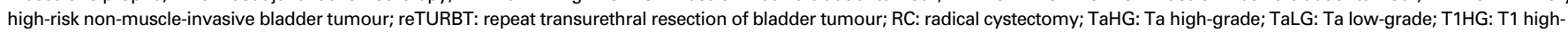
grade; TURP: transurethral resection of prostate. 
Traboulsi et al.

\section{Discussion}

Review by genitourinary pathologist resulted in management changes of a significant percentage of patients. Twelve radical cystectomies were mandated for patients found to have invasive UC on review and two cystectomies were avoided. Furthermore, seven early cystectomies were proposed, as an option for patients deemed at very high-risk for progression on review.

Discrepancy in pathological review for bladder cancer has been shown in few studies. Definite pathological diagnosis is difficult when the studied specimens involve limited samples, such as biopsies. Wayment et al found a $10 \%$ disagreement rate in pathological reports of prostate and bladder specimens after review. ${ }^{16}$ Another study found a discordance rate of $18 \%$ in patients with bladder cancer. ${ }^{17}$ Although discrepancies in review are present across all stages of bladder cancer, review appears to be important in NMIBC-HR tumours. In a multicentre analysis, Van der Meijden assessed the impact of pathology review in Ta and T1 tumours. ${ }^{2}$ Among patients initially classified as T1HG, $10.6 \%$ were reclassified as invasive UC. Another study on 164 patients showed that $15 \%$ of patients initially staged as $\mathrm{T} 1$ were downstaged to Ta and $4 \%$ were upstaged to $\geq \mathrm{T} 2$. The review significantly changed the patients' management. ${ }^{4}$ Our series showed definite management changes in $28.6 \%$ of T1 patients; these results parallel the aforementioned studies in confirming the importance of review in high-risk patients, namely $\mathrm{T} 1 .^{2,4}$

Our study also highlights the importance of classifying patients into risk categories, resulting in potential important management changes after reclassification, despite no change in T stage in some patients. We consider recognizing NMIBC-VHR to be important. Merits of early cystectomy in this instance should be discussed when counselling patients.

Underreporting of CIS and LVI by pathologists in the community is attributed to several reasons. Some may not report negative findings. Interpretation of CIS may be challenging, as these lesions could be interpreted as reactive atypia/dysplasia or vice versa. CIS may also present with high-grade "shoulder" areas that do not demonstrate papillae, or the perceived CIS may be a surveillance biopsy sampling of an early papillary neoplasm. Retraction artifacts, displaced tumour nests, and endothelium with thermal changes often mimic LVI in TURBT specimens.

Similarly, reporting adverse features is also relevant for MIBC. In our proposed treatment plan, NAC was strongly advised in MIBC-HR. Platinum-based NAC confers a small but significant $5 \%$ overall survival advantage over radical cystectomy alone. ${ }^{18}$ Some centres advise NAC for all invasive, organ-confined disease, whereas others (including our institution) have adopted a risk-adapted approach, where NAC is primarily recommended for MIBC-HR. ${ }^{13}$
$\mathrm{VH}$ is prognostically important and could influence therapeutic decisions. ${ }^{15,19} \mathrm{VH}$ is a relatively common finding; however, $44 \%$ of $\mathrm{VH}$ differentiation in $\mathrm{UC}$ is not reported by community pathologists. ${ }^{20}$ Presence of certain histological variants can cause significant management changes, particularly when recognized in conjunction with NMIBC-HR tumours. For example, micropapillary variant with NMIBC is associated with muscle invasion, ${ }^{21}$ decreased response to bacillus Calmette-Guerin (BCG), and high risk of progression where early cystectomy is often advocated to improve survival. ${ }^{22}$ On the other hand, small-cell and lymphoepithelioma-like variants respond well to upfront chemotherapy. ${ }^{15,23}$

In our study, we did not analyze discrepancy in reporting between specialized genitourinary pathologists and 'experienced' general pathologists. Cobblentz et al found no difference in pathological interpretation between those two groups. ${ }^{17}$ Another study showed that a re-evaluation of pathology specimens differed significantly and impacted management; however, this discrepancy remained practically unchanged after the introduction of genitourinary pathology subspecialisation at the institution. ${ }^{24}$

Review pathology could greatly impact management of bladder cancer; nevertheless, the urologist should be aware of the difficulties in interpretation encountered by all pathologists and should look at the results with caution. The material studied in TURBT specimens is often small and scarce, with cauterization artifacts. The challenge in identification of early lamina propria invasion ${ }^{25}$ could lead to understaging of $\mathrm{T} 1$ disease, whereas misinterpretation of muscularis propria with muscularis mucosa would lead to overstaging towards muscle-invasive disease. ${ }^{26} \mathrm{CIS}$ is not always sampled during biopsy and is difficult to differentiate from reactive atypia/dysplasia. Communication between urologist and pathologist is critical for optimal patient care. Urologists should be aware of whether a particular pathologist at their institution is conservative or not in his/her interpretation when deciding on management.

Our study, despite the relatively small number of patients, captured all consecutive consultations in a contemporary period and provides a reliable comparison of clinical management change before and after review. Our study is also unique, as it includes a methodical assessment of all pertinent pathology details from reports of the original and review consultations before classifying patients into risk categories and subsequent clinical management schemes.

\section{Conclusion}

Pathology re-review by genitourinary-specialized pathologists can provide for important stage, grade, and histology changes, in addition to detect $\mathrm{VH}, \mathrm{LVI}$, and concomitant CIS, all of which have the ability to lead important clinical management changes especially for $\mathrm{T} 1$ and $\mathrm{T} 2 \mathrm{blad}-$ 
der tumours. A complete initial pathological report could potentially further decrease the discrepancy between initial and review reports.

Competing interests: Dr. Tanguay has been an advisor for Pfizer and has received a travel grant from Sanofi. Dr. Aprikian has received grants/honoraria from AbbVie, Amgen, Astellas, and Janssen; holds investments in Biosite Inc; and has participated in clinical trials supported by Astellas. Dr. Kassouf is a recipient of a Research Scholar Award from the FRQS. He has also received payment for participating in advisory boards for Amgen, Astellas, and Janssen. The remaining authors report no competing personal or financial interests.

This paper has been peer-reviewed.

\section{References}

1. Kurpad R, Kim W, Rathmell, et al. A multidisciplinary approach to the management of urologic malignancies: Does it influence diagnostic and treatment decisions? Urol Oncol 2011;29:378-82. hitps://doi.org/10.1016/i.urolonc.2009.04.008

2. Van Der Meijden A, Sylvester R, Collette L, et al. The role and impact of pathology review on stage and grade assessment of stages Ta and TI bladder tumours: A combined analysis of five European Organization for Research and Treatment of Cancer Trials. J Urol 2000;16:1533-7. https://doi.org/10.1016/ S0022-5347(05)67022-X

3. Wities JA, Kiemeney LA, Schaafsma HE, et al. The influence of review pathology on study outcome of a randomized, multicentre, superficial bladder cancer trial. Members of the Dutch South East Cooperative Urological Group. Br J Urol 1994;73:172-6. https://doi.org/10.1111/i.1464-410X.1994.tb07487.x

4. van Rhijn BW, van der Kwast TH, Kakiashvili DM, et al. Pathological stage review is indicated in primary pTl bladder cancer. BJU Int 2010;106:206-11. https://doi.org/10.1111/j.1464-410X.2009.09100.x

5. Sobin LH, Gospodariwicz M, Wittekind C, eds. TNM classification of malignant tumours. UICC International Union Against Cancer. 7th edn. Wiley-Blackwell, 2009; pp. 262-5.

6. Sauter $G$, Algaba $F$, Amin $M$, et al. Tumours of the urinary system: Non-invasive urothelial neoplasias. In: Eble JN, Sauter G, Epstein Jl, Sesterhenn IA. WHO classification of tumours of the urinary system and male genital organs. Lyon: IARCC Press, 2004; pp. 110-23.

7. Lopez-Beltran A, Sauter $G$, Gasser T, et al. Tumours of the urinary system: Infiltrating urothelial carcinoma In: Eble JN, Sauter G, Epstein JI, Sesterhenn IA. WHO classification of tumours of the urinary system and male genital organs. Lyon: IARCC Press, 2004; pp. 93-109.

8. Hansel $D E$, Amin MB, Comperat $E$, et al. A contemporary update on pathology standards for bladder cancer: Transurethral resection and radical cystectomy specimens. Eur Urol 2013;63:321-32. https://doi.org/10.1016/i.eururo.2012.10.008

9. Protocol for the examination of specimens from patients with carcinoma of the urinary bladder: College of American Pathologists. Posted June 2012. Available at: http://www.cap.org. Accessed April, 3, 2016.

10. Chang SS, Boorijan $S A$, Chou R, et al. Diagnosis and treatment of non-muscle-invasive bladder cancer: AUA/SUO guideline. J Urol 2016;196;1021-9. https://doi.org/10.1016/i.juro.2016.06.049
11. Kassouf W, Traboulsi SL, Kulkarni GS, et al. CUA guidelines on the management of non-muscle-invasive bladder cancer. Can Urol Assoc J 2015;9:E690-704. htrps://doi.org/10.5489/cuai.3320

12. Culp SH, Dickstein RJ, Grossman HB, et al. Refining patient selection for neoadjuvant chemotherapy before radical cystectomy. J Urol 2014;191:40-7. https://doi.org/10.1016/i.juro.2013.07.061

13. Millikan R, Dinney C, Swanson D, et al. Integrated therapy for locally advanced bladder cancer: Final report of a randomized trial of cystectomy plus adjuvant M-VAC vs. cystectomy with both preoperative and postoperative M-VAC. J Clin Oncol 2001;19:4005-13. https://doi.org/10.1200/JC0.2001.19.20.4005

14. Amin MB. Histological variants of urothelial carcinoma: Diagnostic, therapeutic, and prognostic implications. Mod Pathol 2009;22:S96-118. https://doi.org/10.1038/modpathol.2009.26

15. Black $P C$, Brown $G A$, Dinney $C P$. The impact of variant histology on the outcome of bladder cancer treated with curative intent. Urol Oncol 2009;27:3-7. https://doi.org/10.1016/j.urolonc.2007.07.010

16. Wayment RO, Bourne A, Kay P, et al. Second opinion pathology in tertiary care of patients with urologic malignancies. Urol Oncol 2011;29:194-8. https://doi.org/10.1016/i.urolonc.2009.03.025

17. Coblentz TR, Mills SE, Theodorescu D. Impact of second opinion pathology in the definitive management of patients with bladder carcinoma. Cancer 2001;91:1284-90. https://doi.org/10.1002/10970142(20010401)91:7<1284::AID-CNCR1 130>3.0.C0;2-E

18. Advanced Bladder Cancer (ABC) Meta-analysis Collaboration. Neoadjuvant chemotherapy in invasive bladder cancer: Update of a systematic review and meta-analysis of individual patient data advanced bladder cancer (ABC) meta-analysis collaboration. Eur Urol 2005;48:202-5. https://doi.org/10.1016/i. eururo.2005.04.006

19. Wasco MJ, Daignault S, Zhang $Y$, et al. Urothelial carcinoma with divergent histological differentiation (mixed histological features) predicts the presence of locally advanced bladder cancer when detected at transurethral resection. Urology 2007;70:69-74. https://doi.org/10.1016/i.urology.2007.03.033

20. Shah RB, Montgomery JS, Montie JE, et al. Variant (divergent) histological differentiation in urothelial carcinoma is under-recognized in community practice: Impact of mandatory central pathology review at a large referral hospital. Urol Oncol 2013;31:1650-5. hittps://doi.org/10.1016/i.urolonc.2012.04.009

21. Comperat E, Roupret $M$, Yaxley J, et al. Micropapillary urothelial carcinoma of the urinary bladder: A clinicopathological analysis of 72 cases. Pathology 2010;42:650-4. https://doi.org/10.3109/0031 3025.2010.522173

22. Kamat AM, Dinney CP, Gee JR, et al. Micropapillary bladder cancer: A review of the University of Texas M. D. Anderson Cancer Centre experience with 100 consecutive patients. Cancer 2007;1 10:62-7. https://doi.org/10.1002/cncr.22756

23. Williamson SR, Zhang S, Lopez-Beltran A, et al. Lymphoepithelioma-like carcinoma of the urinary bladder: Clinicopathological, immunohistochemical, and molecular features. Am I Surg Pathol 2011;35:474-83. https://doi.org/10.1097/PAS.0b013e31820f709e

24. Lee MC, Levin HS, Jones JS. The role of pathology review of transurethral bladder tumour resection specimens in the modern era. J Urol 2010;183:921-7. htrps://doi.org/10.1016/i.juro.2009.11.049

25. Tosoni I, Wagner U, Sauter $G$, et al. Clinical significance of interobserver differences in the staging and grading of superficial bladder cancer. BJU Int 2000;85:48-53. https://doi.org/10.1046/j.1464410x.2000.00356.x

26. Paner GP, Ro JY, Wojicik EM, et al. Further characterization of the muscle layers and lamina propria of the urinary bladder by systematic histological mapping: Implications for pathological staging of invasive urothetial carcinoma. Am J Surg Pathol 2007;31:1420-9. https://doi.org/10.1097/PAS.0b013e3180588283

Correspondence: Dr. Wassim Kassouf, Division of Urology, McGill University Health Centre, Montreal, QC, Canada; wassim.kassoư@muhc.mcgill.ca 